\title{
The relationship between findings on magnetic resonance imaging and previous history of low back pain
}

Juichi Tonosu'

Hiroyuki Oka ${ }^{2}$

Ko Matsudaira ${ }^{2}$

Akiro Higashikawa'

Hiroshi Okazaki'

Sakae Tanaka ${ }^{3}$

'Department of Orthopedic Surgery, Kanto Rosai Hospital, Kawasaki, ${ }^{2}$ Department of Medical Research and Management for Musculoskeletal Pain, 22nd Century Medical and Research Center, ${ }^{3}$ Department of Orthopedic Surgery, Faculty of Medicine, The University of Tokyo, Tokyo, Japan
Correspondence: Juichi Tonosu Department of Orthopedic Surgery, Kanto Rosai Hospital, 2 I I-85 I0, I-I, Kizukisumiyoshicho, Nakahara-ku,

Kawasaki, Kanagawa, Japan

Tel +8I 4441 I 313 I

Fax +81444333150

Email juichitohnosu@yahoo.co.jp
This article was published in the following Dove Press journal:

Journal of Pain Research

29 December 2016

Number of times this article has been viewed

Abstract: The objective of this study was to evaluate the relationship between magnetic resonance imaging (MRI) findings and previous low back pain (LBP) in participants without current LBP. Current LBP was defined as LBP during the past month. Previous LBP was defined as a history of medical consultation for LBP. Ninety-one participants without current LBP were included. Sagittal T2-weighted MRI was used to assess the intervertebral space from T12/L1 to L5/S1. These images were classified into five grades based on the Pfirrmann grading system. Furthermore, we evaluated the presence of disk bulging, high-intensity zone, and spondylolisthesis. We compared the MRI findings between groups with (27 participants) and without (64 participants) previous LBP without current LBP. Intraobserver and interobserver kappa values were evaluated. Participants had an average age of 34.9 years; 47 were female and 44 were male; and their average body mass index was $21.8 \mathrm{~kg} / \mathrm{m}^{2}$. Compared to the group of participants without previous LBP, the group of participants with previous LBP had a significantly higher incidence of disk degeneration such as a Pfirrmann grade $\geq 3$, disk bulging, and high-intensity zone in the analyses adjusted by age and sex. There were no significant differences in spondylolisthesis between the groups. An odds ratio of $>10$ was only found for Pfirrmann grade $\geq 3$, ie, a Pfirrmann grade $\geq 3$ was strongly associated with a history of previous LBP in participants without current LBP.

Keywords: disk bulging, low back pain, magnetic resonance imaging, MRI, Pfirrmann grading, previous history, high-intensity zone

\section{Introduction}

Low back pain (LBP) affects most adults at some point in their lives. Approximately $85 \%-90 \%$ of cases are classified as nonspecific LBP. ${ }^{1}$ In the last decade, LBP was continuously found to be the top leading cause of years lived with disability globally. ${ }^{2}$ Similarly, in Japan, LBP is one of the most common causes of health disability, as in other industrialized countries, with a reported lifetime prevalence of $>80 \%$. ${ }^{3}$ Especially in the workplace, LBP is an important and costly medical problem that leads to decreased employee health and productivity. ${ }^{4}$

Magnetic resonance imaging (MRI) can identify underlying pathologies of LBP. However, the importance of MRI findings is unclear and controversial. Some reports have shown that disk degeneration was associated with LBP, ${ }^{5-7}$ while others have shown that there was no relationship between disk degeneration and LBP ${ }^{8,9}$ Although these reports focused on the relationship between disk degeneration and current LBP, there are a few reports on the relationship between MRI findings, including disk degeneration 
and previous LBP. ${ }^{5,10}$ It has been suggested that symptoms of chronic LBP are often fluctuating, and this is a condition with a pattern of exacerbation and remission. ${ }^{11}$ Some individuals have chronic LBP, whereas others have intermittent pain. We anticipate that if physicians know about the predictive MRI findings of recurrent severe LBP, we can selectively educate patients about preventing LBP. Therefore, we hypothesized that people whose lumbar MRI showed disk degeneration would be prone to developing severe LBP, unless they did not have current severe LBP. The purpose of this study was to evaluate the relationship between MRI findings and previous LBP symptoms in participants without current LBP.

\section{Materials and methods}

\section{Study participants}

From September 2005 to March 2006, we recruited volunteers who were personnel at Kanto Rosai Hospital to participate in the study. Ninety-one participants without current LBP were included. We administered a questionnaire to determine whether they had previous LBP symptoms. According to previous reports, current LBP was defined as pain localized between the costal margin and the inferior gluteal folds depicted in a diagram with or without lower extremity pain in the past 1 month. ${ }^{1,12}$ The area was shown diagrammatically on the questionnaire according to a previous study. ${ }^{12}$ Previous LBP was defined as a history of medical consultation for LBP. Medical consultation for LBP is one of the standards for evaluating the severity of LBP. ${ }^{13}$ This indicated that the LBP was not mild. Then, we classified the participants into two groups, those with previous LBP and those without previous LBP. The study was approved by the review board of the Minister of Labor, Health, and Welfare of Japan. Written informed consent was obtained from all individual participants included in the study.

\section{Image assessment}

MRI was performed using a 1.5 T Siemens Symphony scanner (Siemens Healthcare, Erlangen, Germany). The imaging protocol included sagittal T2-weighted fast spin echo (repetition time: $3,500 \mathrm{~ms} /$ echo, echo time: $120 \mathrm{~ms}$, and field of view: $300 \times 320 \mathrm{~mm}$ ). Sagittal T2-weighted images were used to assess the intervertebral space from T12/L1 to L5/S1. Assessment of the MRI scans was performed by an orthopedist (J.T.) who was blinded to the participants' backgrounds. We evaluated the degree of disk degeneration, disk bulging, the high-intensity zone (HIZ), and spondylolisthesis at each level of the spine. The degree of disk degeneration on MRI was classified into five grades based on the Pfirrmann classification system. ${ }^{14}$ In the analysis, we divided Pfirrmann grading into two categories, grades 1-2 and grades 3-5. Disk bulging was defined as displacement of the disk material, usually by $>50 \%$ of the disk circumference and $<3 \mathrm{~mm}$ beyond the edges of the disk space in the axial plane. ${ }^{15}$ As we were only able to evaluate the sagittal planes of MRI scans, we defined disk bulging as posterior disk displacement $<3 \mathrm{~mm}$ and equivalent to the anterior disk displacement in the sagittal plane. We defined HIZ as an area of brightness or high signal intensity located in the posterior annulus on T2-weighted images based on previous literature. ${ }^{16}$ We defined spondylolisthesis as vertebral slips of $>5 \mathrm{~mm}$. To evaluate intraobserver variability, 20 randomly selected MRI scans of the lumbar spine were rescored by the same observer (J.T.) $>1$ month after the first reading. Furthermore, to evaluate interobserver variability, 20 other MRI scans were scored by two orthopedists (J.T. and A.H.) using the same classification.

Finally, we focused on comparing the relationship between the MRI findings and previous LBP.

\section{Statistical analysis}

The kappa statistic was used to summarize the intrareader and interreader reliability of the ratings. The kappa statistics were calculated with linear weights to give less importance to disagreements closer together on an ordinal scale. The schema of Landis and $\mathrm{Koch}^{17}$ was used to interpret the strength of agreement based on the following values: 0 , poor; $0-0.20$, slight; 0.21-0.40, fair; 0.41-0.60, moderate; 0.61-0.80, substantial; and 0.81-1.00, almost perfect. Between-group differences in baseline characteristics were evaluated using the Fisher's exact test for categorical variables and the Student's $t$-test for continuous variables. We compared the MRI findings between groups with and without previous LBP that did not have current LBP by using the Fisher's exact test. Furthermore, we determined the odds ratios of each item using univariate analyses and adjusting the analyses by age and sex. The statistical analyses were performed using the JMP 11.0 software program (SAS Institute, Cary, NC, USA). A $p$-value of $<0.05$ was considered to be significant.

\section{Results}

Of 91 participants, 27 had a history of LBP, which was indicated during medical consultation. The remaining 64 participants did not have any history of LBP. Participants' average age was $34.9 \pm 10.6$ years; 47 were female and 44 were male; and their average body mass index (BMI) was $21.8 \pm 3.0 \mathrm{~kg} / \mathrm{m}^{2}$. The average ages of those who did and did 
Table I Demographic data of the participants

\begin{tabular}{lllll}
\hline Backgrounds & Total, $\mathbf{n}=\mathbf{9 1}$ & $\begin{array}{l}\text { Previous LBP }(+) \\
\text { group, } \mathbf{n}=\mathbf{2 7}\end{array}$ & $\begin{array}{l}\text { Previous LBP (-) } \\
\text { group, } \mathbf{n}=\mathbf{6 4}\end{array}$ & $\begin{array}{l}\mathbf{P} \text {-value } \\
\text { Age (years) }\end{array}$ \\
Sex & $34.9 \pm 10.6$ & $38.3 \pm 10.7$ & $33.5 \pm 10.4$ & $0.0486^{*}$ \\
Female & 47 & $12(25.5)$ & $35(74.5)$ & 0.3718 \\
Male & 44 & $15(34.1)$ & $29(65.9)$ & \\
BMl $\left(\mathrm{kg} / \mathrm{m}^{2}\right)$ & $21.8 \pm 3.0$ & $21.8 \pm 0.6$ & $21.7 \pm 0.4$ & 0.9639 \\
\hline
\end{tabular}

Notes: Data are shown as mean \pm standard deviation or the number of participants $(\%)$. ${ }_{p}<0.05$.

Abbreviations: -, negative; +, positive; LBP, low back pain; BMI, body mass index.

Table 2 Details of the intraobserver and interobserver reliability of Pfirrmann grading, disk bulging, the high-intensity zone, and spondylolisthesis on magnetic resonance imaging reading

\begin{tabular}{llll}
\hline MRI findings & MRI (n) & Kappa & $\mathbf{9 5 \% ~ C l ~}$ \\
\hline $\begin{array}{l}\text { Pfirrmann grading } \\
\text { Intraobserver reliability }\end{array}$ & 20 vs 20 & 0.66 & $0.55-0.77$ \\
$\quad$ Interobserver reliability & 20 vs 20 & 0.64 & $0.52-0.76$ \\
$\begin{array}{l}\text { Disk bulging } \\
\quad \text { Intraobserver reliability }\end{array}$ & 20 vs 20 & 0.60 & $0.39-0.8$ I \\
$\quad$ Interobserver reliability & 20 vs 20 & 0.67 & $0.48-0.87$ \\
$\begin{array}{l}\text { High-intensity zone } \\
\quad \text { Intraobserver reliability }\end{array}$ & 20 vs 20 & 0.85 & $0.64-1.06$ \\
$\quad$ Interobserver reliability & 20 vs 20 & 0.93 & $0.79-1.07$ \\
$\begin{array}{l}\text { Spondylolisthesis } \\
\quad \text { Intraobserver reliability }\end{array}$ & 20 vs 20 & NA & NA \\
Interobserver reliability & 20 vs 20 & NA & NA \\
\hline
\end{tabular}

Abbreviations: $\mathrm{Cl}$, confidence interval; $\mathrm{MRI}$, magnetic resonance imaging; $\mathrm{NA}$, not applicable.

not have a history of LBP were 38.3 and 33.5 years, respectively, which were significantly different $(p=0.0486)$. There were no significant differences in sex and BMI between the groups (Table 1).

The intraobserver and interobserver variabilities for Pfirrmann grading on MRI were 0.66 and 0.64 , respectively. Those for disk bulging were 0.60 and 0.67 , respectively. Those for the HIZ were 0.85 and 0.93 , respectively. In 20 randomly selected MRIs, one observer did not identify spondylolisthesis at all, while the other observer identified spondylolisthesis in two levels of one participant. Thus, the intraobserver and interobserver variabilities for spondylolisthesis could not be calculated (Table 2).

Compared to the group without previous LBP, the group with previous LBP had a significantly higher incidence of disk degeneration such as a Pfirrmann grade $\geq 3$ in at least one spinal level $(p=0.0026)$. In addition, the group with previous LBP had a significantly higher incidence of disk bulging in at least one spinal level than the group without previous LBP $(p=0.0019)$. There were no significant differences in HIZ $(p=0.0883)$ and spondylolisthesis $(p=0.0766)$ between the two groups according to the results of the
Table 3 Magnetic resonance imaging findings at any spinal level in groups with and without previous LBP that did not have current LBP

\begin{tabular}{lllll}
\hline MRI findings & $\begin{array}{l}\text { Total, } \\
\mathbf{n = 9 1}\end{array}$ & $\begin{array}{l}\text { Previous } \\
\text { LBP (+) } \\
\text { group, } \\
\mathbf{n = 2 7}\end{array}$ & $\begin{array}{l}\text { Previous } \\
\text { LBP (-) } \\
\text { group, } \\
\mathbf{n = 6 4}\end{array}$ & $\begin{array}{l}\mathbf{p} \text {-value } \\
\end{array}$ \\
\hline Pfirrmann grade $\geq 3$ & $69(75.8)$ & $26(96.3)$ & $43(67.2)$ & $0.0026^{*}$ \\
Disk bulging + & $48(52.3)$ & $21(77.8)$ & $27(42.2)$ & $0.0019 *$ \\
High-intensity zone + & $19(20.9)$ & $9(33.3)$ & $10(15.6)$ & 0.0883 \\
Spondylolisthesis + & $4(4.4)$ & $3(11.1)$ & $1(1.6)$ & 0.0766 \\
\hline
\end{tabular}

Notes: Data are shown as the number of participants (\%). ${ }^{*} p<0.05$.

Abbreviations: -, negative; +, positive; LBP, low back pain; MRI, magnetic resonance imaging.

Fisher's exact test (Table 3). Regarding the findings for each spinal level, compared to the group without previous LBP, the group with previous LBP had a significantly higher incidence of disk degeneration such as a Pfirrmann grade $\geq 3$ at the T12/L1 $(p=0.0350), \mathrm{L} 3 / 4(p=0.0232), \mathrm{L} 4 / 5$ ( $p=$ $0.0005)$, and $\mathrm{L} 5 / \mathrm{S} 1(p=0.0026)$ levels; and disk bulging at the $\mathrm{L} 2 / 3(p=0.0277), \mathrm{L} 3 / 4(p=0.0113), \mathrm{L} 4 / 5(p=0.0018)$, and L5/S1 levels ( $p=0.0081$; Table 4$)$. The findings of HIZ were almost all observed at the L4/5 and L5/S1 levels. Spondylolisthesis was only observed at the L4/5 and L5/S1 levels. In univariate analyses, the odds ratios of a Pfirrmann grade $\geq 3$, disk bulging, HIZ, and spondylolisthesis were 12.7, 4.8, 2.7 , and 7.9, respectively. There were significant differences for a Pfirrmann grade $\geq 3$ ( $p=0.0009)$ and disk bulging $(p=0.0015)$ in univariate analyses. In the adjusted analyses by age and sex, the odds ratios of the aforementioned four items were 10.5, 4.2, 3.1, and 6.6, respectively, and there were significant differences for a Pfirrmann grade $\geq 3(p=0.0065)$, disk bulging ( $p=0.0047)$, and HIZ ( $p=0.0405$; Table 5).

\section{Discussion}

Among the participants in this study, $\sim 30 \%$ had previous LBP, which was determined during the medical consultation. As in many industrialized countries, LBP is one of the most common health disabilities in Japan. In a population-based 
Table 4 Pfirrmann grade and disk bulging at each spinal level in groups with and without previous LBP that did not have current LBP

\begin{tabular}{|c|c|c|c|c|c|}
\hline MRI findings & Level & Total, $\mathbf{n}=91$ & $\begin{array}{l}\text { Previous LBP }(+) \\
\text { group, } \mathbf{n}=27\end{array}$ & $\begin{array}{l}\text { Previous LBP }(-) \\
\text { group, } \mathrm{n}=64\end{array}$ & $p$-value \\
\hline \multirow[t]{6}{*}{ Pfirrmann grade $\geq 3$} & $\mathrm{TI} / \mathrm{LI}$ & $18(19.8)$ & $9(33.3)$ & $9(14.1)$ & $0.0350 *$ \\
\hline & $\mathrm{LI} / 2$ & $22(24.2)$ & $9(33.3)$ & $13(20.3)$ & 0.1851 \\
\hline & $\mathrm{L} 2 / 3$ & $30(33.0)$ & $10(37.0)$ & $20(31.3)$ & 0.5917 \\
\hline & $\mathrm{L} 3 / 4$ & $44(48.4)$ & $18(66.7)$ & $26(40.6)$ & $0.0232 *$ \\
\hline & L4/5 & $56(61.5)$ & $24(88.9)$ & $32(50.0)$ & $0.0005^{*}$ \\
\hline & L5/SI & $56(61.5)$ & $23(85.2)$ & $33(51.6)$ & $0.0026 *$ \\
\hline \multirow[t]{6}{*}{ Disk bulging $(+)$} & $\mathrm{TI} / \mathrm{LI}$ & $2(2.2)$ & I (3.7) & $\mathrm{I}(\mathrm{I} .6)$ & 0.5245 \\
\hline & $\mathrm{LI} / 2$ & $\mathrm{I}(\mathrm{I} . \mathrm{I})$ & I (3.7) & $0(0.0)$ & 0.1216 \\
\hline & $\mathrm{L} 2 / 3$ & $2(2.2)$ & $2(7.4)$ & $0(0.0)$ & $0.0277^{*}$ \\
\hline & $\mathrm{L} 3 / 4$ & $5(5.5)$ & $4(14.8)$ & I (I.6) & $0.0113 *$ \\
\hline & L4/5 & $35(38.5)$ & $17(63.0)$ & $18(28.1)$ & $0.0018 *$ \\
\hline & $\mathrm{L} 5 / \mathrm{SI}$ & $35(38.5)$ & $16(59.3)$ & $19(29.7)$ & $0.008 I^{*}$ \\
\hline
\end{tabular}

Notes: Data are shown as the number of participants (\%). ${ }^{*} p<0.05$.

Abbreviations: -, negative; +, positive; LBP, low back pain; MRI, magnetic resonance imaging.

Table 5 Odds ratio, $95 \% \mathrm{Cl}$, and $p$-value from univariate analyses and analyses adjusted by age and sex for magnetic resonance imaging findings of groups with and without previous LBP that did not have current LBP

\begin{tabular}{|c|c|c|c|c|c|c|}
\hline \multirow[t]{2}{*}{ MRI findings } & \multicolumn{3}{|c|}{ Univariate analyses } & \multicolumn{3}{|c|}{ Age-adjusted and sex-adjusted analyses } \\
\hline & Odds ratio & $95 \% \mathrm{Cl}$ & p-value & Odds ratio & $95 \% \mathrm{Cl}$ & $p$-value \\
\hline Pfirrmann grade $\geq 3$ & 12.7 & $2.43-234.18$ & $0.0009 *$ & 10.5 & I.78-202.09 & $0.0065 *$ \\
\hline Disk bulging & 4.8 & $1.79-14.55$ & $0.0015^{*}$ & 4.2 & $1.54-13.15$ & $0.0047^{*}$ \\
\hline High-intensity zone & 2.7 & $0.94-7.78$ & 0.0652 & 3.1 & $1.05-9.42$ & $0.0405^{*}$ \\
\hline Spondylolisthesis & 7.9 & $0.96-163.50$ & 0.0551 & 6.6 & $0.74-|4| .7 \mid$ & 0.0923 \\
\hline
\end{tabular}

Note: $* p<0.05$.

Abbreviations: $\mathrm{Cl}$, confidence interval; LBP, low back pain; MRI, magnetic resonance imaging.

survey, the lifetime and 4-week LBP prevalence was $83 \%$ and $36 \%$, respectively. ${ }^{3}$ Therefore, LBP is one of the common causes of disability. In the current study, we precisely defined the region of LBP, which seemed to be important for standardizing the study protocol for LBP. ${ }^{1,12}$ We also defined previous LBP as a history of medical consultation for LBP, which can exclude mild previous LBP. There was a significant difference in age between the two groups. Considering that disk degeneration progresses with advancing age, ${ }^{6}$ the analyses performed in our study can be considered as appropriate.

The intraobserver and interobserver variabilities for each MRI finding were greater than moderate for all evaluated items.

MRI findings consistent with Pfirrmann grade $\geq 3$, especially at the lower lumbar disk level, disk bulging, and HIZ were associated with previous LBP. Spondylolisthesis was not associated with previous LBP. There were significant differences between the groups in terms of a Pfirrmann grade $\geq 3$, disk bulging, and HIZ according to the analyses adjusted by age and sex. The odds ratio of only the Pfirrmann grade $\geq 3$ was $>10$, ie, a Pfirrmann grade $\geq 3$ is strongly associated with a history of previous LBP in those without current LBP.
Pfirrmann grading indicates the degree of disk degeneration. ${ }^{14}$ We divided the grading into two groups for the purpose of analysis. We regarded those with grades 1-2 as having no or little disk degeneration and those with grades $3-5$ as having some degree of disk degeneration. There have been many reports on the relationship between current LBP and disk degeneration; ${ }^{5-7}$ however, none have reported on the relationship between previous LBP and Pfirmann grading. Videman et $\mathrm{l}^{10}$ showed that disk height narrowing was associated with previous LBP, but they did not use Pfirrmann grading. Since disk height narrowing was classified as Pfirrmann grade $5,{ }^{14}$ this can be interpreted as implying that severe disk degeneration was associated with previous LBP. Although we included Pfirrmann grades 5, 3, and 4, which did not indicate severe disk height narrowing, our findings were almost consistent with the previous study's findings in terms of disk degeneration.

Pfirrmann grade $\geq 3$ at T12/L1, L3/4, L4/5, and L5/S1 was associated with previous LBP. A large population study showed that disk degeneration was most commonly affected at L5-S1 and L4-L5, ${ }^{6}$ which corresponds with our findings. A mechanical study showed that the range of motion in the 
lower lumbar segments was significantly smaller than that in the upper segments. ${ }^{18}$ The small range of motion at the intervertebral disk space can cause the load to increase at the disk, which can easily cause disk degeneration. This may be a reason why disk degeneration was more prominent at the lower lumbar disk levels than at the upper disk levels in the current study.

Disk bulging was associated with previous LBP. Regarding each spinal level, disk bulging at the L2/3, L3/4, L4/5, and L5/S1 levels was associated with previous LBP. Although the $p$-values were inclined to be smaller at lower disk levels than at upper disk levels, previous LBP was associated with disk bulging at almost all the lumbar disk levels. Some studies have shown that disk bulging was frequently observed in asymptomatic subjects, and it was concluded that there was no relationship between disk bulging and current LBP, ${ }^{19,20}$ whereas another study of a meta-analysis showed a strong relationship.? As for previous LBP, Videman et $\mathrm{a}^{10}$ showed that disk bulging was not associated with previous LBP. Our findings were not consistent with previous findings in terms of disk bulging.

A systematic review of the relationship between MRI findings and current LBP showed that disk degeneration and disk bulging are associated with current LBP, especially in younger adults, and this relationship disappears in older populations. ${ }^{7}$ Although the study did not mention previous LBP, we can assume that older adults with disk degeneration or disk bulging who do not have current LBP may have had LBP when they were younger. These results correspond with our findings.

The HIZ was often observed at the level of L4/5 and L5/ $\mathrm{S} 1$, and it was associated with previous LBP. There was a significant difference in the analyses adjusted by age and sex $(p=0.0405)$, although no significant relationship was found using the Fisher's exact test and univariate analyses. Aprill and Bogduk ${ }^{16}$ reported a strong correlation between the annular high signal intensity zone and positive provocative discography. Some study has shown that the HIZ was associated with current LBP. ${ }^{21}$ Dongfeng et $\mathrm{al}^{22}$ performed a histological study on excised disks with a HIZ, and they concluded that the HIZ may be a specific signal for the inflammatory reaction of a painful disk. Conversely, other studies have shown that the HIZ was frequently observed in asymptomatic subjects. ${ }^{7,19,20}$ As for previous LBP, Videman et $\mathrm{a}^{10}$ showed that annular tear on axial MRI scans was associated with previous LBP. However, there has been no report on the relationship between the HIZ and previous LBP.

Spondylolisthesis was considered to be one of the findings of lumbar spine instability. ${ }^{23}$ Considering that instability of the lumbar spine can cause LBP, it was assumed that those who had spondylolisthesis were inclined to have LBP. ${ }^{24}$ However, some reports identified no significant relationship between spondylolisthesis and current LBP. ${ }^{7,25}$ Furthermore, Hasegawa et $\mathrm{al}^{26}$ showed that the radiological findings of spondylolisthesis cannot indicate instability. However, there has been no report on the relationship between spondylolisthesis and previous LBP. In our study, only four participants who did not have current LBP had spondylolisthesis. Three of these had previous LBP, and only one did not have previous LBP. There was no significant relationship between spondylolisthesis and previous LBP; however, this may be attributed to the small number of spondylolisthesis cases in our study.

One systematic review showed that HIZ and spondylolisthesis are not associated with current LBP, even in younger adults. ${ }^{7}$ Therefore, the aforementioned information about disk degeneration or disk bulging does not correspond with HIZ and spondylolisthesis.

While some chronic LBP patients show continuous pattern, others have intermittent pattern. ${ }^{11}$ Therefore, there was a possibility that the participants in our study who had previous LBP without current LBP had chronic LBP as intermittent pain. They did not have LBP at the time of participation; however, they may suffer recurrent LBP in the future as a natural course in the intermittent LBP pattern. Based on the results of the current study, MRI findings consistent with Pfirrmann grade $\geq 3$, disk bulging, and HIZ may be one of the predictive signs of recurrent severe LBP. Thus, we can selectively educate patients about preventing LBP.

There were some limitations to the current study. First, we did not evaluate end plate changes because we only analyzed sagittal T2-weighted images and T1-weighted images were unavailable, even though Modic change has been considered to be associated with LBP. $^{5}$ In a population-based study on 975 participants, Teraguchi et $\mathrm{a}^{27}$ showed that the combination of disk degeneration and end plate changes was highly associated with current LBP, whereas disk degeneration alone was not associated with current LBP. There is no previous report on the relationship between end plate changes and previous LBP, and we did not assess this relationship in our study. Second, we only analyzed sagittal images. Disk bulging and the HIZ can sometimes be visible at the posterolateral sides; however, these can be underestimated. Third, there was selection bias among our study participants, as they were volunteers from all types of employment at the hospital and did not represent the general population.

\section{Conclusion}

MRI findings consistent with Pfirrmann grading $\geq 3$, especially at the lower lumbar disk level, disk bulging, and HIZ 
were associated with previous LBP. In addition, spondylolisthesis was not associated with previous LBP. These findings may be one of the predictive signs of recurrent severe LBP.

\section{Disclosure}

The authors report no conflicts of interest in this work.

\section{References}

1. Krismer M, van Tulder M, Low Back Pain Group of the Bone and Joint Health Strategies for Europe Project. Strategies for prevention and management of musculoskeletal conditions. Low back pain (non-specific). Best Pract Res Clin Rheumatol. 2007;21(1): 77-91.

2. Vos T, Flaxman AD, Naghavi M, et al. Years lived with disability (YLDs) for 1160 sequelae of 289 diseases and injuries 1990-2010: a systematic analysis for the Global Burden of Disease Study 2010. Lancet. 2012;380(9859):2163-2196.

3. Fujii T, Matsudaira K. Prevalence of low back pain and factors associated with chronic disabling back pain in Japan. Eur Spine J. 2013;22(2):432-438.

4. Feldman JB. The prevention of occupational low back pain disability: evidence-based reviews point in a new direction. J Surg Orthop Adv. 2004;13(1):1-14.

5. Kjaer P, Leboeuf-Yde C, Korsholm L, Sorensen JS, Bendix T. Magnetic resonance imaging and low back pain in adults: a diagnostic imaging study of 40-year-old men and women. Spine (Phila Pa 1976). 2005;30(10):1173-1180.

6. Cheung KM, Karppinen J, Chan D, et al. Prevalence and pattern of lumbar magnetic resonance imaging changes in a population study of one thousand forty-three individuals. Spine. 2009;34(9): 934-940.

7. Brinjikji W, Diehn FE, Jarvik JG, et al. MRI findings of disc degeneration are more prevalent in adults with low back pain than in asymptomatic controls: a systematic review and meta-analysis. AJNR Am J Neuroradiol. 2015;36(12):2394-2399.

8. Berg L, Hellum C, Gjertsen Ø, et al; Norwegian Spine Study Group. Do more MRI findings imply worse disability or more intense low back pain? A cross-sectional study of candidates for lumbar disc prosthesis. Skeletal Radiol. 2013;42(11):1593-1602.

9. Endean A, Palmer KT, Coggon D. Potential of magnetic resonance imaging findings to refine case definition for mechanical low back pain in epidemiological studies: a systematic review. Spine (Phila Pa 1976). 2011;36(2):160-169.

10. Videman T, Battié MC, Gibbons LE, Maravilla K, Manninen H, Kaprio J. Associations between back pain history and lumbar MRI findings. Spine (Phila Pa 1976). 2003;28(6):582-588.

11. Tamcan O, Mannion AF, Eisenring C, Horisberger B, Elfering A, Müller $\mathrm{U}$. The course of chronic and recurrent low back pain in the general population. Pain. 2010;150(3):451-457.

12. Dionne CE, Dunn KM, Croft PR, et al. A consensus approach toward the standardization of back pain definitions for use in prevalence studies. Spine (Phila Pa 1976). 2008;33(1):95-103.
13. Mikkonen P, Heikkala E, Paananen M, et al. Accumulation of psychosocial and lifestyle factors and risk of low back pain in adolescence: a cohort study. Eur Spine J. 2016;25(2):635-642.

14. Pfirrmann CW, Metzdorf A, Zanetti M, Hodler J, Boos N. Magnetic resonance classification of lumbar intervertebral disc degeneration. Spine (Phila Pa 1976). 2001;26(17):1873-1878.

15. Fardon DF, Milette PC; Combined Task Forces of the North American Spine Society; American Society of Spine Radiology; American Society of Neuroradiology. Nomenclature and classification of lumbar disc pathology. Recommendations of the combined task forces of the North American Spine Society, American Society of Spine Radiology, and American Society of Neuroradiology. Spine (Phila Pa 1976). 2001;26(5):E93-E113.

16. Aprill C, Bogduk N. High-intensity zone: a diagnostic sign of painful lumbar disc on magnetic resonance imaging. $\mathrm{Br} J$ Radiol. 1992;65(773):361-369.

17. Landis JR, Koch GG. The measurement of observer agreement for categorical data. Biometrics. 1977;33(1):159-174.

18. Lee SH, Daffner SD, Wang JC. Does lumbar disk degeneration increase segmental mobility in vivo? Segmental motion analysis of the whole lumbar spine using kinetic MRI. J Spinal Disord Tech. 2014;27(2):111-116.

19. Stadnik TW, Lee RR, Coen HL, Neirynck EC, Buisseret TS, Osteaux MJ. Annular tears and disk herniation: prevalence and contrast enhancement on MR images in the absence of low back pain or sciatica. Radiology. 1998;206(1):49-55.

20. Weishaupt D, Zanetti M, Hodler J, Boos N. MR imaging of the lumbar spine: prevalence of intervertebral disk extrusion and sequestration, nerve root compression, end plate abnormalities, and osteoarthritis of the facet joints in asymptomatic volunteers. Radiology. 1998;209(3):661-666.

21. Schellhas KP, Pollei SR, Gundry CR, Heithoff KB. Lumbar disc high-intensity zone. Correlation of magnetic resonance imaging and discography. Spine (Phila Pa 1976). 1996;21(1):79-86.

22. Dongfeng R, Hou S, Wu W, et al. The expression of tumor necrosis factor- $\alpha$ and CD68 in high-intensity zone of lumbar intervertebral disc on magnetic resonance image in the patients with low back pain. Spine (Phila Pa 1976). 2011;36(6):E429-E433.

23. McGregor AH, McCarthy ID, Doré CJ, Hughes SP. Quantitative assessment of the motion of the lumbar spine in the low back pain population and the effect of different spinal pathologies of this motion. Eur Spine J. 1997;6(5):308-315.

24. Alfieri A, Gazzeri R, Prell J, Röllinghoff M. The current management of lumbar spondylolisthesis. J Neurosurg Sci. 2013;57(2):103-113.

25. Kalichman L, Kim DH, Li L, Guermazi A, Berkin V, Hunter DJ. Spondylolysis and spondylolisthesis: prevalence and association with low back pain in the adult community-based population. Spine (Phila Pa 1976). 2009;34(2):199-205.

26. Hasegawa K, Kitahara K, Shimoda H, et al. Lumbar degenerative spondylolisthesis is not always unstable: clinicobiomechanical evidence. Spine (Phila Pa 1976). 2014;39(26):2127-2135.

27. Teraguchi M, Yoshimura N, Hashizume H, et al. The association of combination of disk degeneration, end plate signal change, and Schmorl node with low back pain in a large population study: the Wakayama Spine Study. Spine J. 2015;15(4):622-628.
Journal of Pain Research

\section{Publish your work in this journal}

The Journal of Pain Research is an international, peer reviewed, open access, online journal that welcomes laboratory and clinical findings in the fields of pain research and the prevention and management of pain. Original research, reviews, symposium reports, hypothesis formation and commentaries are all considered for publication.

\section{Dovepress}

The manuscript management system is completely online and includes a very quick and fair peer-review system, which is all easy to use. Visit http://www.dovepress.com/testimonials.php to read real quotes from published authors. 